\title{
A new minimally invasive technique for correction of pectus carinatum
}

\author{
Wei Ping, Shengling Fu, Yangkai Li, Jun Yu, Ni Zhang, Xiangning Fu and Yixin Cai*
}

\begin{abstract}
Background: The Abramson technique for the correction of pectus carinatum (PC) is commonly performed worldwide. However, the postoperative complications of this technique related to bar fixation, including wire breakage and bar displacement, are relatively high. In this study, a new minimally invasive technique for correction of PC is described, in which the pectus bar is secured by bilateral selected ribs, and for which no special fixation to the rib is needed.

Methods: The procedure was performed by placing the pectus bar subcutaneously over the sternum with both ends of the bar passing through the intercostal space of the selected rib at the anterior axillary line. The protruding sternum was depressed by the bar positioned in this 2 intra- and 2 extra-thorax manners. Between October 2011 and September 2019, 42 patients with PC underwent this procedure.

Results: Satisfactory cosmetic results were obtained in all the patients. The mean operation time was 87.14 min, and the mean postoperative stay was 4.05 days. Wound infection occurred in 3 patients, 2 were cured by antibiotics, and 1 received bar removal 4 months after the initial operation due to the exposure of the implant resulting from uncontrolled infection. Mild pneumothorax was found in 3 patients and cured by conservative treatment. One patient suffered from hydropneumothorax, which was treated with chest drainage. The bars were removed at a mean duration of 24.4 months since primary repair in 20 patients without recurrence.
\end{abstract}

Conclusions: This new technique for minimally invasive correction of PC deformity is a safe and feasible procedure yielding good results and minimal complications.

Keywords: Pectus carinatum, Minimally invasive correction, Pectus bar, Fixation

\section{Introduction}

Pectus carinatum (PC) is a chest deformity characterized by the excessive protrusion of the sternum and the adjacent costal cartilages. It is one of the most common chest wall deformities, with a reported prevalence of about $0.06 \%$, second only to pectus excavatum $[1,2]$. At present, the minimal access procedure for the repair of PC [3], first introduced in 2005 by Abramson, in which a steel bar is placed subcutaneously over the sternum and

*Correspondence: caiyixin28@163.com

Department of Thoracic Surgery, Tongji Hospital, Tongji Medical College, Huazhong University of Science and Technology, No. 1095 Jiefang Road, Wuhan 430030, Hubei Province, China fixed to the ribs with wires, has been widely applied with good cosmetic results [4-6]. In the Abramson technique, the bar is placed entirely outside the chest wall, and thus all the force on the sternum is sustained by wires. Wire breakage is a common postoperative complication in this procedure, with a reported incidence of $5.2-16.6 \%[4,7$, 8], and reaching as high as $100 \%$ in Lee et al's report [9]. It should be noted that early wire breakage is the primary cause of bar displacement that results in orthopedic failure and re-operation [10].

In this article, we describe a new minimally invasive technique for correction of pectus carinatum, in which a modeled pectus-bar is placed over the sternum through the subcutaneous tunnel with both ends passed through original author(s) and the source, provide a link to the Creative Commons licence, and indicate if changes were made. The images or other third party material in this article are included in the article's Creative Commons licence, unless indicated otherwise in a credit line to the material. If material is not included in the article's Creative Commons licence and your intended use is not permitted by statutory regulation or exceeds the permitted use, you will need to obtain permission directly from the copyright holder. To view a copy of this licence, visit http://creativecommons.org/licenses/by/4.0/. The Creative Commons Public Domain Dedication waiver (http://creativecommons.org/publicdomain/zero/1.0/) applies to the data made available in this article, unless otherwise stated in a credit line to the data. 
the intercostal space of the selected rib at the anterior axillary line. In this way, the bar is driven into and then brought out of the thorax on both sides ( 2 intra- and 2 extra-thorax) without special fixation to the ribs. The protruding sternum is depressed by force provided by the bilaterally selected ribs exerting force onto the bar without manual pressure.

\section{Patients and methods}

\section{Patients}

From October 2011 to September 2019, 42 patients (39 males and 3 females) with PC underwent the surgical correction in this new procedure at our department. Records of these patients were retrospectively reviewed. Written consent was obtained from patients or from their parents if their age was under 18 years. The study was conducted in accordance with the principles of the Declaration of Helsinki.

The mean age of the patients was 13.69 years (range 5-17 years). All patients presented with chondrogladiolar PC, with 34 being symmetric and 8 being asymmetric. Preoperative examinations were performed on all patients and included laboratory tests, cardiovascular evaluation [electrocardiography (ECG)] and radiological investigations [chest X-ray or computed tomography (CT)]. Evaluation of the chest wall flexibility was routinely performed on all patients by compression of the protruding area with the examiner's hand with the patient in a supine position or leaning against a wall. There were no abnormal findings on routine preoperative cardiac and pulmonary function evaluations. The mean value of the preoperative Haller index obtained from 27 patients who received a CT scan was 1.95 (range 1.54-2.45). All patients presented with cosmetic complaints and had not received any prior orthopedic treatment.

\section{Surgical technique}

Preoperative measurement to determine the size of the orthopedic pectus bar was performed using the horizontal distance between the midaxillary line on both sides at the level of maximal protrusion of the sternum.

General anesthesia with endotracheal intubation was administered in all patients. The patient was positioned in the supine position with both arms abducted. Two transverse incisions, $3 \mathrm{~cm}$ each, were made on the midaxillary line at the level of the maximal protrusion (Fig. 1). Further dissection was performed to expose the rib at the anterior axillary line, of which the upper and lower intercostal spaces were each divided. Blunt dissection was performed subcutaneously towards the sternum via the incisions at both sides with a long-curved clamp, thus creating a subcutaneous tunnel. The pectus introducer passed through the subcutaneous tunnel from a skin incision to the contralateral incision (Fig. 2). A polyvinyl chloride (PVC) tube was attached to the introducer and guided through the subcutaneous tunnel, and then exited from both incisions. The 2 ends of the PVC tube were separately inserted into the upper intercostal space and pulled out from the lower intercostal space of the rib at the anterior axillary line. The pectus bar was modeled into a convex shape according to the particular characteristics of the deformity. One tip of the bar was inserted into the PVC tube lumen. With its convexity facing posteriorly, the bar passed under the selected rib through the intercostal space that had been prepared as described above. As the tip of the bar was being forwarded through the subcutaneous tunnel and reached the opposite side,

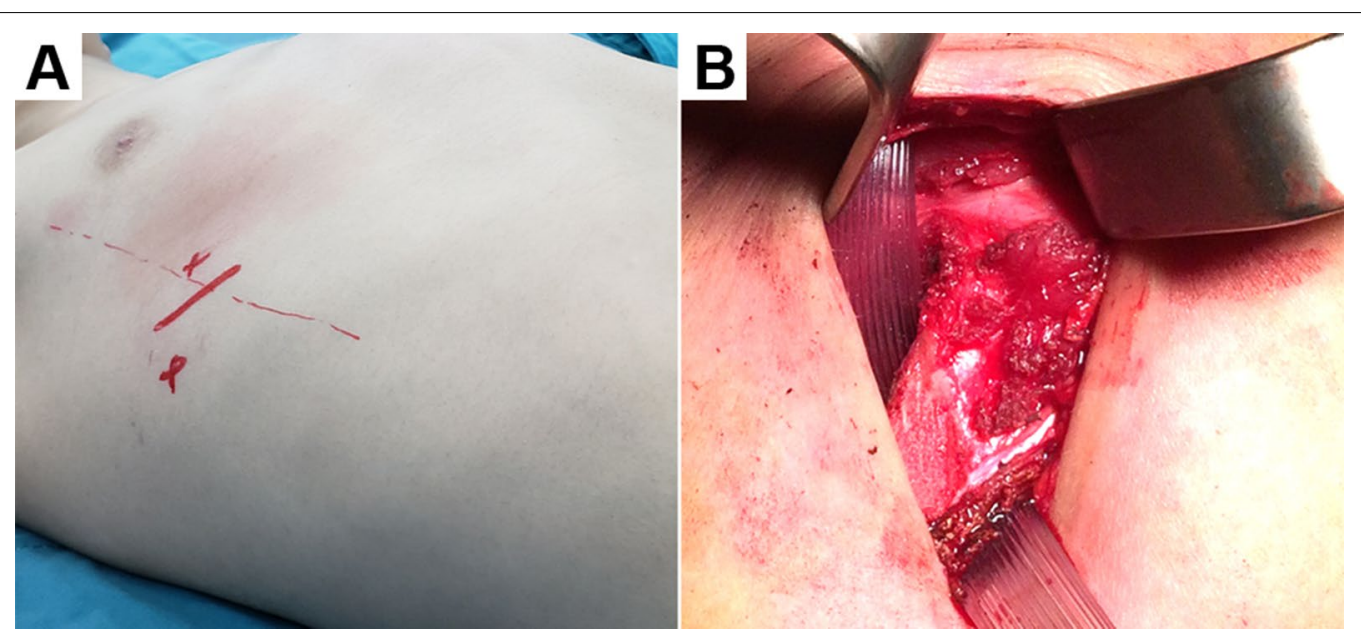

Fig. 1 a Preoperative marking of the rib at the anterior axillary line. The upper and lower intercostal spaces were planned to divide. b A polyvinyl chloride tube was pulled out from the upper intercostal space to the lower intercostal space of the rib at the anterior axillary line 


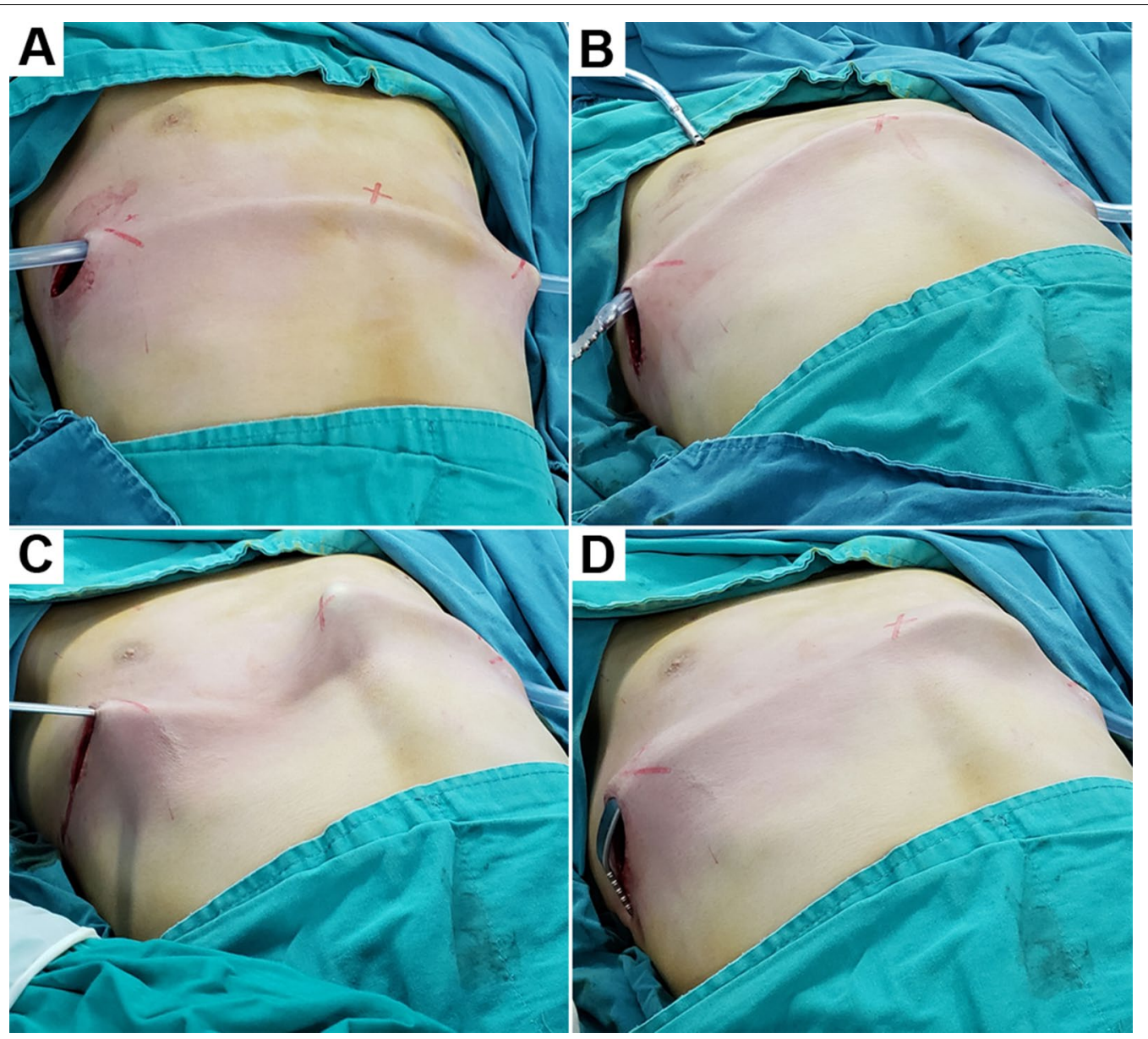

Fig. 2 Operative procedures. a A PVC tube was passed through the subcutaneous tunnel from a skin incision to the contralateral incision. b One tip of the pectus bar was inserted into the PVC tube lumen. c The pectus bar was guided to pass through the subcutaneous by the PVC. $\mathbf{d}$ The pectus bar was flipped over $180^{\circ}$ and advanced into and back out of the chest by passing from the upper intercostal space to the lower intercostal space. PVC: polyvinyl chloride

the bar was flipped over $180^{\circ}$ and advanced into and back out of the chest from the upper to the lower intercostal space of the rib at the anterior axillary line, with the guidance of the PVC tube. One or two stabilizers were fixed to the chest wall muscles with absorbable sutures. The lung was expanded under visual control before the closure of the thorax, and the wound was then closed in layers.

Posteroanterior and lateral chest X-rays were obtained $24 \mathrm{~h}$ after surgery to identify the bar location and to look for pneumothorax. Pain control was maintained with intravenous patient-controlled analgesia (IVPCA) using hydromorphone during the postoperative $48 \mathrm{~h}$, followed by oral oxycodone. Antibiotics were used $48-72 \mathrm{~h}$ after surgery. Patients were advised to avoid contact sports within 3 months of surgery. Patient satisfaction was evaluated with the answers provided on questionnaires completed on postoperative day 3 and after bar removal.

\section{Statistical analysis}

Normally distributed continuous data were expressed as mean \pm standard deviation. Statistical analyses were performed using SPSS (ver. 20; SPSS, Inc., Chicago, IL, USA) for Windows.

\section{Results}

All patients and/or their guardian reported excellent $(\mathrm{n}=37)$ or good $(\mathrm{n}=5)$ cosmetic results. A single bar was placed in every patient without any significant blood loss. In total, 2 stabilizers were equipped in 31 patients, while only 1 stabilizer was equipped in the other 11 . The mean operation time and duration of postoperative stay were $87.14 \mathrm{~min}$ (range 55-125 $\mathrm{min}$ ) and 4.05 days (range 1-12 days), respectively. The mean follow-up after the operation was 28.5 months (c 3-63 months). The 3-dimensional imaging and Symmetric pectus carinatum 

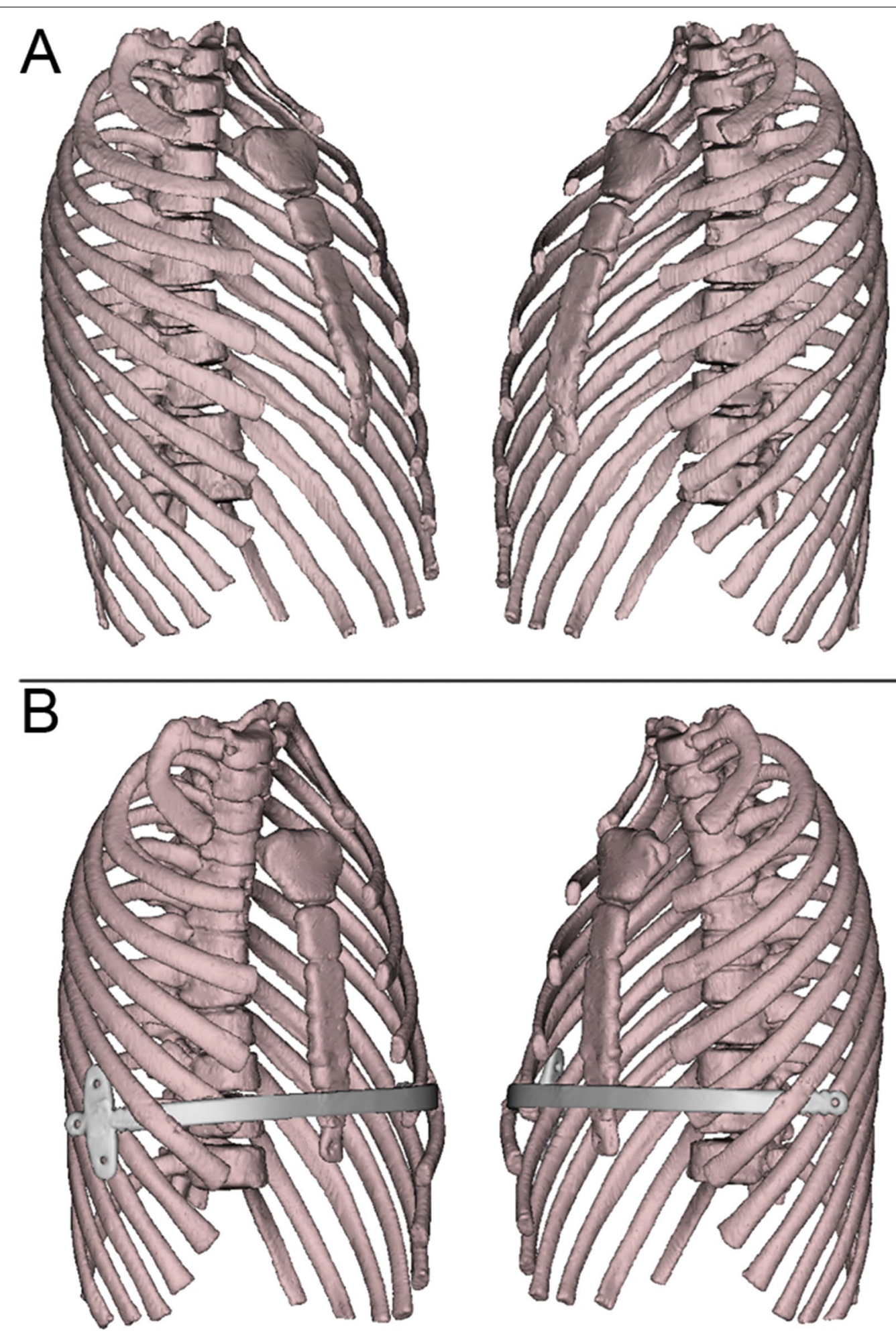

Fig. 3 The 3-dimensional imaging of a 13-year-old patient's computed tomography before $\mathbf{a}$ and after $\mathbf{b}$ the operation 
of a 13-year-old patient before and after the operation are shown in Figs. 3 and 4.

Wound infections occurred in 3 patients, with 2 being cured by antibiotics accordingly, and 1 presenting with persistent infection in the left incision, which resulted in the exposure of the implant. Despite antibiotic treatment and a debridement operation, the infection could not be controlled. The pectus bar in this patient was removed 4 months after the initial operation. Mild pneumothorax was diagnosed in 3 patients, but no drainage was required. One patient suffered from hydropneumothorax, which was treated with chest drainage.

There was no displacement of the bar during the follow-up period. A slight lateral shift of the bar occurred in 1 patient 6 weeks after the operation, but no recurrence of the malformation and no further shift were observed during the follow-up. All patients discontinued analgesics within 1 month after the operation without complaint of persistent pain. Finally, 20 patients underwent the removal of the bar between 2 and 3 years after surgery without recurrences of the malformation.

\section{Discussion}

While the pathogenic mechanisms for PC remain unclear, the disease has a lower incidence rate than pectus excavatum and accounts for $6-22 \%$ of all chest wall deformities $[2,11]$. It is more common in males with a male-female ratio of 4:1, and typically presents during childhood and aggravates dramatically during pubertal growth [12]. There are different types of PC according to the maximum point of the deformity: the chondrogladiolar form is the most common variety (involving the lower sternum) with symmetric or asymmetric protrusion, while the chondromanubrial form is much less common (involving the upper sternum) [13]. In contrast to pectus excavatum, pectus carinatum deformities are more evident and difficult to conceal with clothing or posture. As a result, the patients with PC suffer from poor self-confidence, feelings of inferiority, and are hesitant or refuse to participate in sports or social activities, which are all harmful to the patient's psychological health.

Treatment options for PC include nonoperative treatment and operative treatment. Nonoperative treatment for PC employs a specially designed orthotic chest brace to apply compression on the protruding sternum to achieve the correction of the deformity. This technique has been proven to be effective and associated with advantages of non-invasiveness and low morbidity [14, 15]. However, as it requires long-term application of the brace and does not immediately present a satisfactory result, non-compliance is frequent [16].

The conventional Ravitch operation and its modified procedures for PC $[17,18]$, consisting of open incision and resection of costal cartilages, are substantially

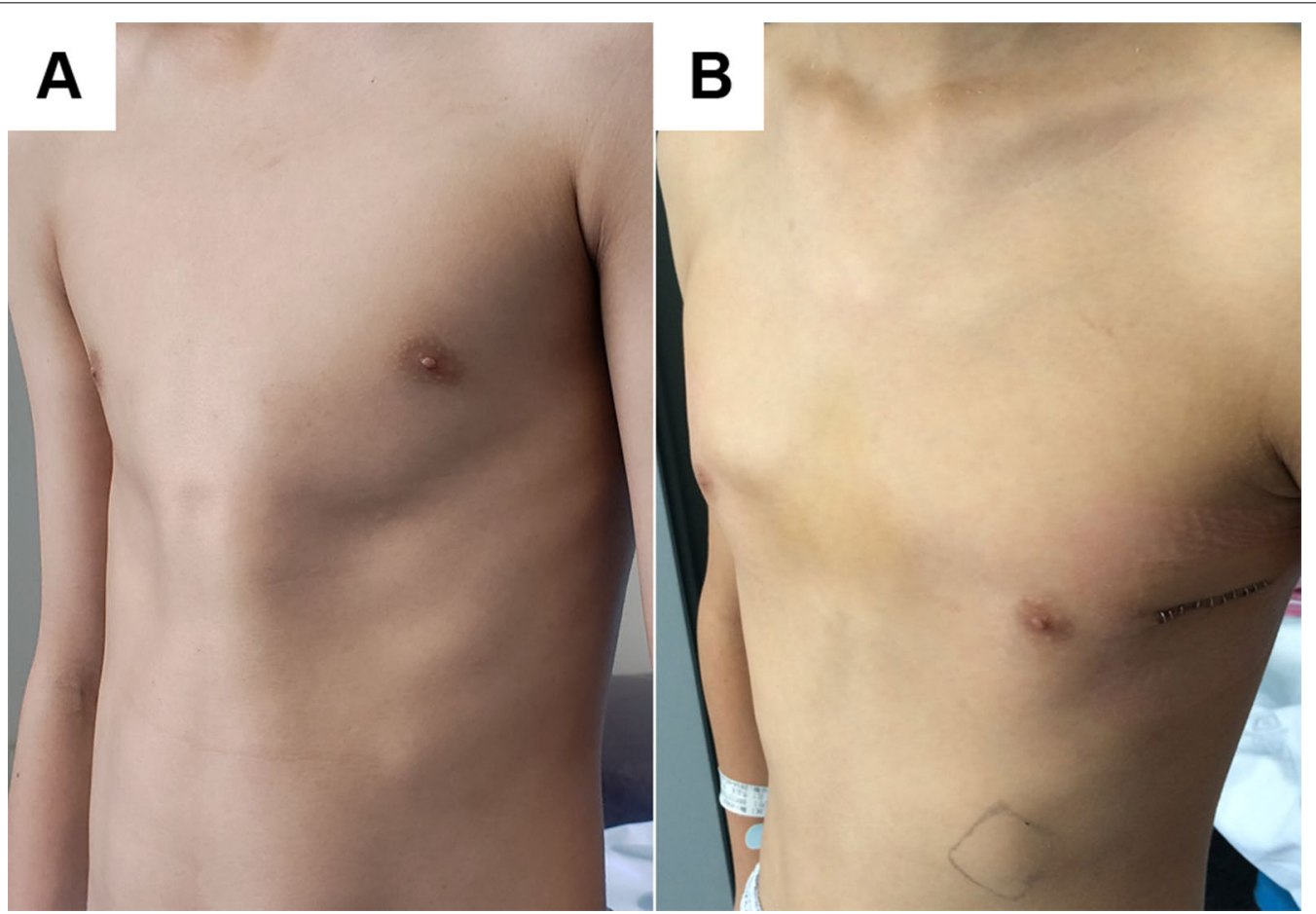

Fig. 4 Symmetric pectus carinatum of a 13-year-old patient before $\mathbf{a}$ and after $\mathbf{b}$ surgery 
invasive and associated with considerable postoperative pain and an obviously visible scar. The minimally invasive procedure for repair of $\mathrm{PC}$, introduced by Abramson, has been performed widely with good cosmetic results and less postoperative complications. However, at least 4 ribs are involved in the fixation system, and postoperative wire breakage is difficult to avoid as the entire force working against the sternum is sustained by the wires. Although various modifications to the Abramson procedure have been applied, the essential principle of the surgery is still the same. Early wire breakage is the primary cause of bar displacement that results in orthopedic failure and re-operation. In addition, since both ends of the metal bars are fixed to the chest wall, the growth and development of the chest may be restricted.

In our technique, the pectus bar is placed over the sternum through the subcutaneous tunnel, with both ends passing through the intercostal spaces of the selected rib at the anterior axillary line. The protruding sternum is depressed by force being exerted by the selected ribs onto the bar. Since the intra- and extra-thorax placement of the bar results in an "autologous" force and stability, neither manual compression nor special wire fixation is needed. Furthermore, due to the exemption from the fixation of the bar to the bilateral ribs, this procedure can eliminate the restriction on the growth of the chest. Meanwhile, this procedure has an added advantage as the bar corrects the chest contour and simultaneously expands the chest laterally which produces a better cosmetic result. Finally, this operation can be performed with the conventional Nuss pectus bar and instrument, without any specially designed apparatus.

The most significant characteristic of our technique is that the bar passes through the thorax 4 times (2 intraand 2 extra-thorax). The technique in principle is similar to the method proposed by Kálmán and Hock and their colleagues $[19,20]$, in which the bar is passed into or out of the chest parasternal using the finger for blind guidance. In contrast to this method, our procedure presented here is simpler and safer and does not entail a risk of injury to the heart or the great vessels, since the bar is passed through the thorax under direct vision. Compared with Tarhan's technique [21], our procedure further simplifies the operation in the same safety setting and does not require a thoracoscope or presternal incision.

Unlike pectus excavatum, which is characterized by progressive aggravation before adolescence, the deformity of PC is not apparent in childhood but will be rapidly aggravated and reach its physically and psychologically disturbing peak during puberty. According to our experience, the best candidates for the minimally invasive correction are $12-18$ years old.
However, the decision of surgery is based on the flexibility of the chest wall rather than the age. Preoperative evaluation of the chest wall flexibility, by compression of the protruding area with the examiner's hand, while the patient is taking a supine position or leaning against a wall, should be routinely performed for judging whether if a thorax is flexible enough to be corrected. The contraindications for a bar correction are non-malleable, rigid thoraces, as the chondromanubrial type of PC or very asymmetric deformities are more suitable for treatment with the open techniques $[4,19]$.

Eight patients with asymmetric deformity of chondrogladiolar type underwent a correction in our procedure and received good cosmetic results. Therefore, besides symmetric PC, we believe that this technique could also be considered a valid method for the correction of asymmetric PC in selected patients.

There was 1 case of uncontrolled wound infection, which ultimately resulted in the failure of the correction due to the removal of the pectus bar and stabilizers prior to the planned date. This should be ascribed to the insufficient coverage of the bar and stabilizer. The implants should be placed under and well covered by the muscle tissue to avoid subcutaneous exudate. Overall, we consider the morbidity of postoperative complications to be lower. The risk of wire breakage and bar displacement, as frequently observed in the Abramson technique, is avoided due to the fact that the implant is not fixed to the ribs.

Taken together, compared with Abramson procedure and other techniques, the advantages of our procedure are that there are (i) no complications with wire breakage or bar displacement, (ii) no potential restriction on the growth of the chest wall, (iii) no risk of injury to the heart or great vessels; and that (iv) the chest wall can be expanded laterally for a better appearance.

This study has several limitations. First, this is a retrospective study from a single center, which is limited by the small sample size. Surgical skill level needs to be considered in a study of this nature. However, this new minimally invasive technique for 42 patients with $\mathrm{PC}$ in our hospital was performed by 3 different skilled surgeons with excellent technique. Given that satisfactory cosmetic results were obtained in all the patients, we believe it is worth spreading this safe and feasible technique for chondrogladiolar $\mathrm{PC}$ in other centers. Second, all the patients enrolled in the study were chondrogladiolar PC and only 20 patients underwent the removal of the bar, further experience with more patients is necessary to evaluate the long-term results and to study whether this technique is applicable to other forms of PC. 


\section{Conclusion}

In conclusion, this preliminary study demonstrated that the new technique for minimally invasive correction of PC deformity is a safe and feasible procedure yielding good results and minimal complications.

\section{Abbreviations}

PC: Pectus carinatum; ECG: Electrocardiography; CT: Computed tomography; PVC: Polyvinyl chloride; IVPCA: Intravenous patient-controlled analgesia.

\section{Acknowledgements}

None.

\section{Authors' contributions}

YC: Conceptualization; Formal analysis; Methodology; Software; Writingoriginal; draft; Writing-review \& editing. WP: Formal analysis; Methodology; Software; draft; Writing-review \& editing. SF: Investigation; Resources; Writingreview \& editing. YL: Investigation; Resources; Writing-review \& editing. JY: Investigation; Resources; Writing-review \& editing. NZ: Conceptualization; Investigation; Resources; Methodology; Writing-review \& editing. XF: Conceptualization; Methodology; Supervision; Visualization; Writing-review \& editing. All authors read and approved the final manuscript.

\section{Funding}

None.

\section{Availability of data and materials}

All data generated or analyzed during this study are included in this article.

\section{Declarations}

\section{Ethics approval and consent to participate}

This retrospective study was approved by the Ethics Committee of Huazhong University of Science and Technology, Tongji Hospital, that also waived the requirement of informed consent for the use of the patient's medical data.

\section{Consent for publication}

Not applicable.

\section{Competing interests}

None of the authors have any potential competing interest.

Received: 2 January 2021 Accepted: 19 September 2021

Published online: 28 September 2021

\section{References}

1. Goretsky MJ, Kaelly RJ, Croitoru D, Nuss D. Chest wall anomalies: pectus excavatum and pectus carinatum. Adolesc Med Clin. 2004;15(3):455-71.

2. Robicsek F, Watts LT. Pectus carinatum. Thorac Surg Clin. 2010:20(4):563-74.
3. Abramson $\mathrm{H}$. A minimally invasive technique to repair pectus carinatum Preliminary report. Arch Bronconeumol. 2005;41(6):349-51.

4. Abramson H, D'Agostino J, Wuscovi S. A 5-year experience with a minimally invasive technique for pectus carinatum repair. J Pediatr Surg. 2009:44(1):118-24.

5. Bilgin M. Early results of minimal invasive surgery in patients with pectus carinatum. Turk J Thorac Cardiovasc Surg. 2012;20:307-11.

6. Abramson H, Aragone X, Blanco JB, Ciano A, Abramson L. Minimally invasive repair of pectus carinatum and how to deal with complications. J Vis Surg. 2016;2:64.

7. Yuksel M, Lacin T, Ermerak NO, Sirzai EY, Sayan B. Minimally invasive repair of pectus carinatum. Ann Thorac Surg. 2018;105(3):915-23.

8. Yuksel M, Bostanci K, Evman S. Minimally invasive repair of pectus carinatum using a newly designed bar and stabilizer: a single-institution experience. Eur J Cardiothorac Surg. 2011;40(2):339-42.

9. Lee SY, Song IH, Lee SJ. Minimal invasive extrathoracic presternal compression using a metal bar for correction of pectus carinatum. Pediar Surg Int 2014:30(1):25-30.

10. Ozkaya M, Bilgin M. Minimally invasive repair of pectus carinatum: a retrospective analysis based on a single surgeon's 10 years of experience. Gen Thorac Cardiovasc Surg. 2018;66(11):653-7.

11. Franco KL. Advanced therapy in thoracic surgery. London: BC Decker Inc.; 2005. p. 145-51.

12. Fonkalsrud EW. Surgical correction of pectus carinatum: lessons learned from 260 patients. J Pediatr Surg. 2008;43(7):1235-43.

13. Desmarais TJ, Keller MS. Pectus carinatum. Curr Opin Pediatr. 2013:25(3):375-81.

14. Sesia SB, Holland-Cunz S, Hacker FM. Dynamic compression system: an effective nonoperative treatment for pectus carinatum: a single center experience in Basel. Switzerland Eur J Pediatr Surg. 2016;26(6):481-6.

15. Lopez M, Patoir A, Varlet F, Perez-Etchepare E, Tiffet T, Villard A, Tiffet O. Preliminary study of efficacy of dynamic compression system in the correction of typical pectus carinatum. Eur J Cardiothorac Surg. 2013;44(5):e316-9.

16. Frey AS, Garcia VF, Brown RL, Inge TH, Ryckman FC, Cohen AP, Durrett G, Azizkhan RG. Nonoperative management of pectus carinatum. J Pediatr Surg. 2006;41(1):40-5.

17. Ravitch MM. Operative correction of pectus carinatum (Pigeon Breast). Ann Surg. 1960;151(5):705-14

18. Lester CW. Pigeon breast (pectus carinatum) and other protrusion deformities of the chest of developmental origin. Ann Surg. 1953:137(4):482-9.

19. Kalman A. Initial results with minimally invasive repair of pectus carinatum. J Thorac Cardiovasc Surg. 2009;138(2):434-8.

20. Hock A. Minimal access treatment of pectus carinatum: a preliminary report. Pediar Surg Int. 2009;25(4):337-42.

21. Tarhan T, Meurer A, Tarhan O. Combined extra-/intrathoracic correction of pectus carinatum and other asymmetric chest wall deformities: a novel technique. Oper Orthop Traumatol. 2018;30(6):469-78.

\section{Publisher's Note}

Springer Nature remains neutral with regard to jurisdictional claims in published maps and institutional affiliations.

Ready to submit your research? Choose BMC and benefit from:

- fast, convenient online submission

- thorough peer review by experienced researchers in your field

- rapid publication on acceptance

- support for research data, including large and complex data types

- gold Open Access which fosters wider collaboration and increased citations

- maximum visibility for your research: over 100M website views per year

At BMC, research is always in progress.

Learn more biomedcentral.com/submissions 